\title{
Does Madopar Have a Role in the Treatment of Prolonged Disorders of Consciousness? A Call for Randomized Controlled Trials
}

\author{
Christian Saleh Agnieszka Andrykiewicz Margret Hund-Georgiadis \\ REHAB Basel, Clinic for Neurorehabilitation and Paraplegiology, Basel, Switzerland
}

Keywords

Rehabilitation $\cdot$ Madopar $\cdot$ Disorders of consciousness $\cdot$ Clinical trials

\begin{abstract}
It is suggested that dopaminergic treatment may contribute to accelerated improvement in patients with a disorder of consciousness (DoC). Dopamine is an important stimulatory neurotransmitter, which plays a key role in alertness, arousal, behavior, emotion, cognition, and motor function. We discuss our experience with Madopar in 2 patients with DoC and review the literature on dopaminergic medication in patients with DoC.
\end{abstract}

(c) 2021 The Author(s).

Published by S. Karger AG, Basel

\section{Introduction}

The comatose state is defined as unresponsive wakefulness syndrome [1], previously known as vegetative state (VS) if basic functions (breathing and sleep-wake cycles) are maintained. The pioneering work resides to Jennet and Plum [2] who coined the term VS and described it as wakefulness without awareness. The unresponsive wakefulness syndrome requires that the patient does not follow commands, is unable for intelligible verbal or gestural responses, and incapable of localizing or motor responses secondary to relevant external stimuli. When the patient shows visual fixation and pursuit, localization to external physical stimuli, and automatic motor response, the diagnosis of minimally conscious state (MCS) minus is made [3]. Simple command following or intentional communication classifies for MCS plus, followed by emergence from MCS, which is not considered anymore disorder of consciousness (DoC) [4]. 
Several pharmacological treatment strategies for DoC were proposed in the past, such as GABA agonists, antiepileptica, antidementiva, antidepressiva, and dopaminergica [5]. The largest focus for DoC received the treatment with dopaminergic drugs.

Dopamine is an important stimulatory neurotransmitter, which plays a key role in alertness, arousal, behavior, emotion, cognition, and motor function. Dopamine has not only a critical role at the substantia nigra/striatum level but also through the basal ganglia-thalamus network exerts influence on the dorsolateral prefrontal cortex and limbic areas [6-8]. Attempts to explain the organic correlate of consciousness and foremost the rational of dopamine in the treatment of DoC patients were forwarded by several authors [6-10]. Based on the mesocircuit hypothesis in normal wakeful condition, dopamine neurons in the striatum inhibit the pallidum resulting in reduced inhibitory activity on the thalamus [9]. Activating thalamic and cortical projections lead in turn to stimulation of the striatum. In brain injury secondary to diffuse deafferentation, thalamostriatal and corticostriatal projections are reduced resulting in a reduced striatal activity ultimately leading to an increased thalamic inhibition [9]. Fridman et al. [6] showed based on PET study with [11-C] raclopride a dopaminergic deficit in traumatic brain injury (TBI) MCS patients mainly affecting the presynaptic neurons, which project from the ventral tegmentum area (VTA)-substantia nigra to the striato-thalamic areas. Dopaminergic deficit appears to be the consequence of a post-traumatic cellular dysfunction (e.g., secondary inflammatory injury) of the enzyme tyrosine hydroxylase, and administration of L-DOPA reverses the presynaptic dopamine deficit by restoring dopamine biosynthesis from the ventral tegmentum-substantia nigra territories [6]. The potential central role of the VTA in consciousness was evidenced also by Spindler et al. [7], showing in TBI patients VTA disconnection from the percuneus and posterior cingulate areas, a main default mode network node implicated in consciousness [8]. Interestingly within this context to note that also in patients with Parkinson's disease, lesions of dopaminergic cell groups in the VTA projecting on the forebrain lead to reduction in behavioral arousal [8].

Only a few studies have described the use of dopaminergic medication in patients with DoC [11-16]. Although these studies were case reports, they all documented positive and prompt clinical improvement following dopaminergic treatment. We present our experience with Madopar in 2 patients with DoC. Patients with medications (modafinil, melatonin, amantadine, and methylphenidate) or complications (such as infections, epileptic seizures, and bleedings) affecting the vigilance we excluded from our case report as possible confounders to the effect of Madopar. Additionally, we review the literature on dopaminergic medication in DoC.

\section{Case Report}

A 58 years man presented with intracranial bleeding following a fall from 6-m altitude at work. His initial computed tomography (CT) scan showed a midline shift of $15 \mathrm{~mm}$ to the right with a left-sided subdural hematoma and multi-located subarachnoidal hemorrhages (Fig. 1a-d). The patient's past medical history was significant for diabetes mellitus type 2, coronary heart disease, and nicotine abuse. A decompressive hemicraniectomy was performed. His Glasgow Coma Scale (GCS) on admission was 7 out of 15 (eye response: 2 out of 4/upon pain application; verbal response: 1 out of 5/incomprehensible sounds; and motor response: 4 out of $6 /$ flexion to withdraw from pain). His initial Coma-Recovery Scale-Revised (CRS-R) was of 12/23. We initiated 115 days from the primary event a treatment with Madopar with an initial dose of $62.5 \mathrm{mg}$ twice daily that we increased over a circa 2 months period to a daily dose of $437.5 \mathrm{mg}$. The patient improved on the CRS-R from 13 (score at Madopar start) over 2 months to a CRS-R of $22 / 23$. He could respond to questions with nodding or shaking of the head, move the

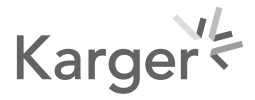




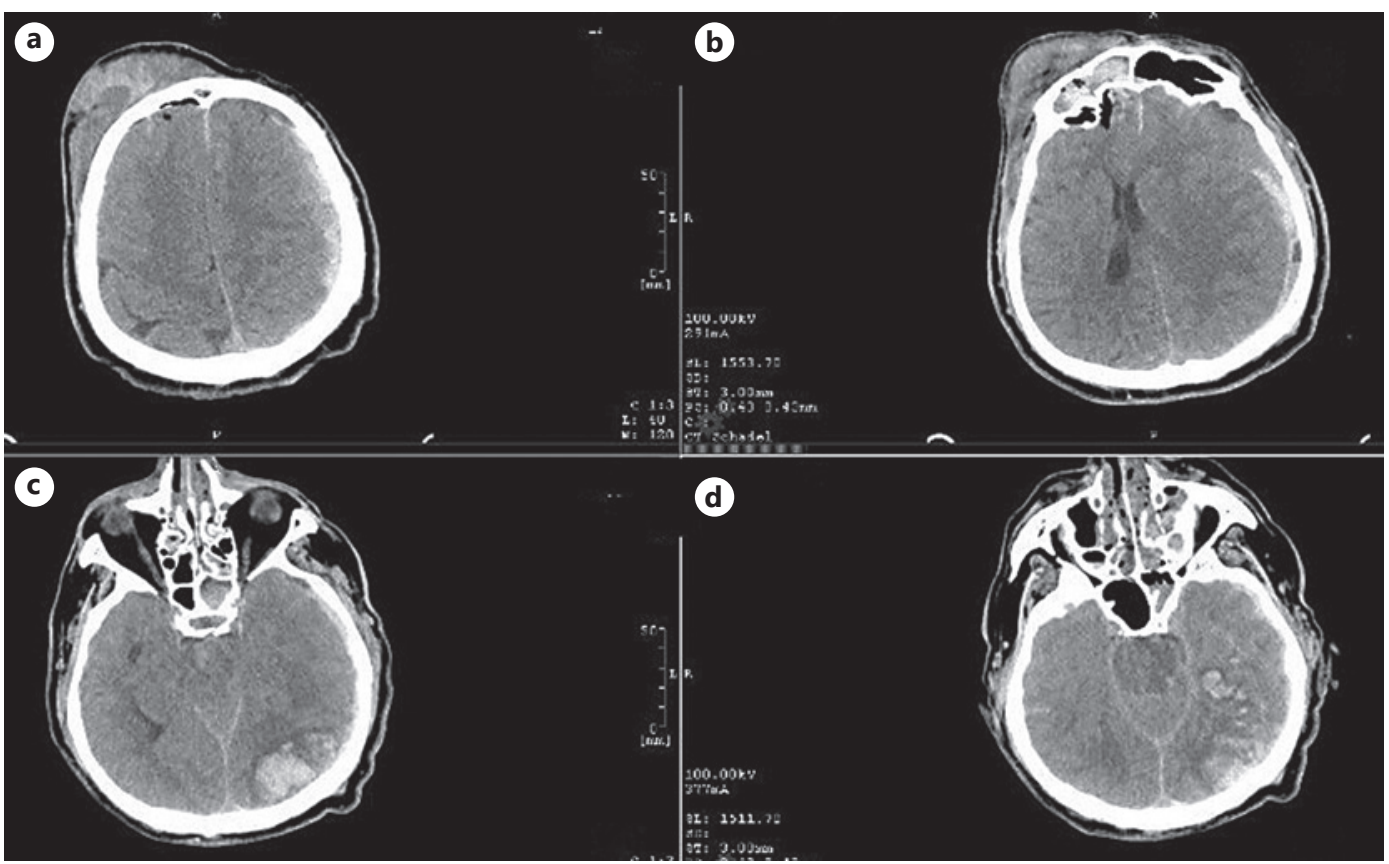

Fig. 1. a-d CT (axial slices) showing midline shift of $15 \mathrm{~mm}$ to the right, a left-sided subdural hematoma with a maximum width of $10 \mathrm{~mm}$, parieto-occipital cerebral hemorrhagic contusions, a bilateral frontal subarachnoid hemorrhage, as well as left-sided temporo-parieto-occipital and right-sided parieto-occipital subarachnoid hemorrhages. A large right frontal subgaleal hematoma. CT, computed tomography.

fork or the glass to his mouth, and put (with support) his T-Shirt. He remained in our rehabilitation clinic for 6 months.

A second patient, a 47-year-old female patient, suffered an acute disseminated encephalomyelitis. She presented initially with agitation, nausea, vomitus, and a left-sided hemiparesis. GCS was 6 out of 15 (eye response: 1/no eye opening; verbal response: 1/no verbal response; and motor response: 4/flexion withdrawal from pain). Her brain imaging (magnetic resonance imaging [MRI] with contrast enhancement) showed diffuse white matter cerebro-cerebellar as well as brainstem lesions (Fig. 2a-d). An electroencephalogram (EEG) evidenced light but nonspecific diffuse changes (foremost in form of delta slowing in the central regions) without any signs of epileptic potentials or increased cerebral excitability. CRS-R was $3 / 23$. A highdose steroid treatment was started for 5 days followed by 5 cycles of plasmapheresis. To enhance the level of consciousness, initial treatment consisted in amantadine. She opened spontaneously the eyes (without fixation) and could localize to pain stimulation. As the electrocardiogram (ECG) showed a QTc prolongation ( $>500 \mathrm{~ms}$ ), amantadine was stopped and piracetam commenced. As under piracetam no improvement in vigilance was observed, the treatment was stopped. Two months after the primary event, a therapy with Madopar was initiated, initially $125 \mathrm{mg}$ twice daily and gradually titrated up to Madopar $250 \mathrm{mg} 3$ times daily. GCS improved to 11-12 (eye response: 4/spontaneous opening; verbal response: 2/incomprehensible sounds; and motor response: 5-6/localizing pain-obeying commands). The patient improved on the CRS-R from 8 points (pre-Madopar) to 18 points (under Madopar) within circa 4 months. More importantly, from the aforementioned total 10 points improvement a 6 points amelioration was seen already within the first 4 weeks of Madopar treatment. The patient developed a spontaneous arm movement activity, but without being able to use it for daily routine activity. She was not able for basic (verbal as not verbal) communication. After 5 months of rehabilitation with an intensive program encompassing physio- ergo- logo- and 


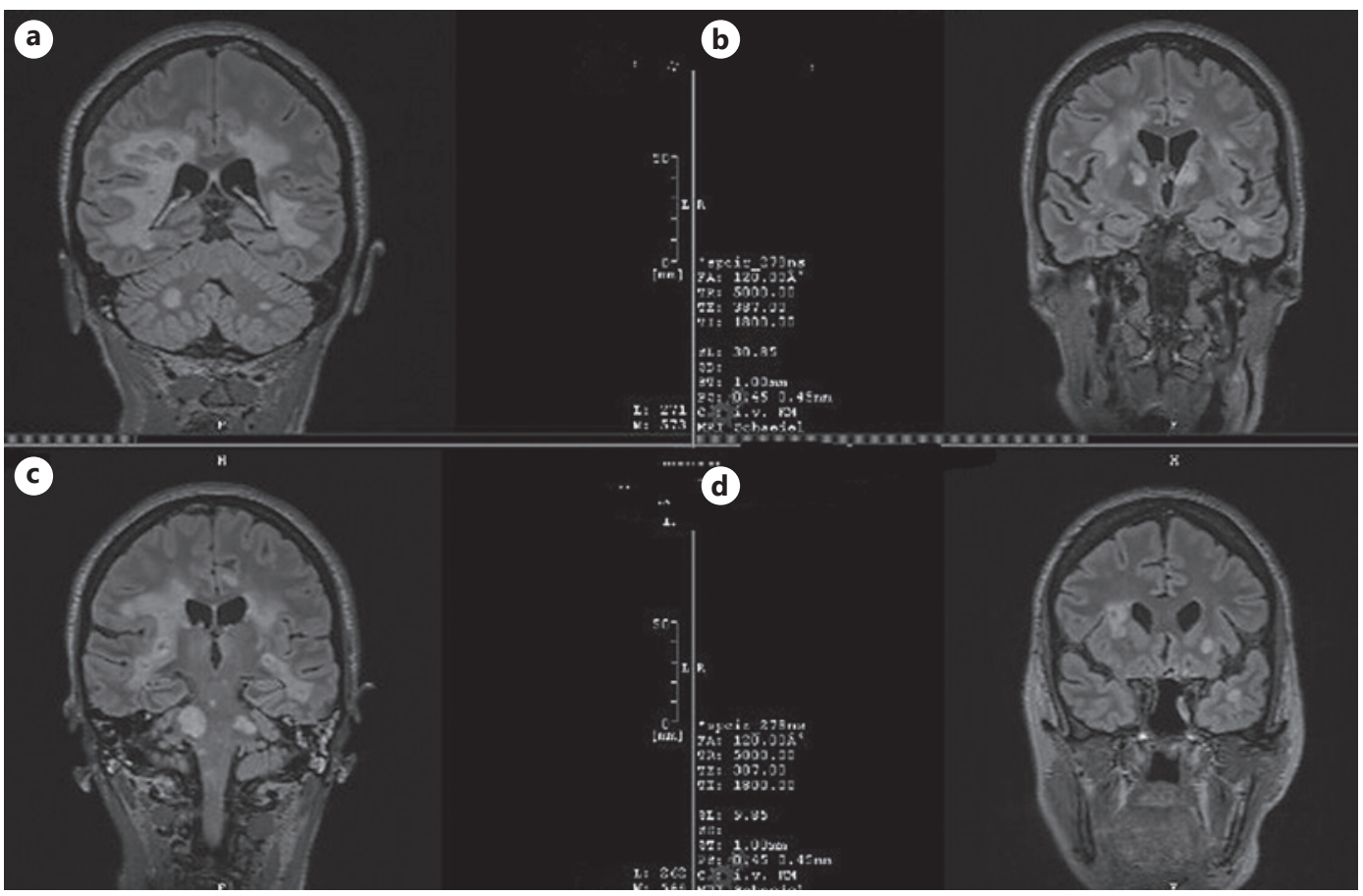

Fig. 2. a-d MRI (coronal slices) with contrast enhancement showing diffuse white matter lesions in supra- and infratentorial areas as well as at the level of the pons. MRI, magnetic resonance imaging.

animal-assisted therapies, she could be discharged (on Madopar $750 \mathrm{mg} / \mathrm{day}$ ) in a MCS minus state in a nursing facility.

\section{Literature Review on L-Dopa, Bromocriptine, and Apomorphine}

\section{Levodopa}

Levodopa (L-dopa) 100/25 mg 3×/day proved to be clinically beneficial in a 62-year-old patient reported by Bancalari et al. [11]. The patient had suffered a cerebellar artery aneurysm rupture which left her in MCS. She showed spontaneous eye opening paralleled by motor function improvement 4 days after initiation of treatment. Eight days after initiation of treatment, she was able to say her first comprehensible words, and 4 weeks later, the patient could interact through hand-signs with the examiner. Ugoya and Akinyemi [12] reported on 11 patients ( 4 women and $7 \mathrm{men}$ ) in VS following brain injury. Brain imaging in most patients showed white matter lesions at the level of the temporal or parietal corticomedullary junction or in the splenium of the corpus callosum. Dopaminergic treatment was commenced between 1 and 6 months from injury. Initial treatment consisted in L-dopa/carbidopa of $100 \mathrm{mg} / 25 \mathrm{mg}$ twice daily gradually increased to a daily dose of $375 \mathrm{mg}$. In 9 of the 11 patients, an improvement of the state of consciousness was observed within 10 days. The authors concluded that dopaminergic medication may be beneficial foremost in patients with lesions to the basal ganglia and related dopaminergic pathways. Matsuda et al. [13] reported 3 VS patients after severe head injury treated 3-12 months after accident with levodopa/benserazide $(n=2)$ at 100/25 mg three times daily and levodopa/carbidopa $(n=1)$ at 100/10 mg three times daily. All 3 patients had parkinsonian symptoms and MRI evidence of midbrain lesions. One of the patients, a 14-year-old boy, was able to walk without walking aid and even return to school 1 year after 
Table 1. Literature review: Demographics and imaging findings

\begin{tabular}{|c|c|c|c|c|c|c|}
\hline First author & Patients, $n$ & Gender & $\begin{array}{l}\text { Age, years, } \\
>3 \text { : mean (SD) }\end{array}$ & Cause & $\begin{array}{l}\text { Conscious } \\
\text { state (before } \\
\text { dopamine) }\end{array}$ & Brain imaging \\
\hline $\begin{array}{l}\text { Bancalari } \\
\text { et al. [11] }\end{array}$ & 1 & $\mathrm{f}$ & 62 & NTAR & MCS & $\begin{array}{l}\text { MRI: intraventricular } \\
\text { hemorrhage, } \\
\text { hydrocephalus }\end{array}$ \\
\hline $\begin{array}{l}\text { Matsuda } \\
\text { et al. [13] }\end{array}$ & 3 & $\mathrm{~m}$ & $14,27,51$ & $3 \mathrm{HI}$ & PVS & $\begin{array}{l}\text { MRI: P1-3: lesion } \\
\text { midbrain }\end{array}$ \\
\hline $\begin{array}{l}\text { Ugoya and } \\
\text { Akinyemi [12] }\end{array}$ & 11 & $\mathrm{f}: 4 ; \mathrm{m}: 7$ & $42(20.6)$ & $\begin{array}{l}3 \mathrm{RTA}, \\
2 \text { assault, } \\
1 \text { CO-Intox., } \\
2 \mathrm{ICH}, 1 \mathrm{UK}, \\
1 \mathrm{SE}\end{array}$ & PVS & $\begin{array}{l}\text { MRI: EDH, thalamic } \\
\text { hemorrhage, diffuse } \\
\text { lesions, SDH }\end{array}$ \\
\hline $\begin{array}{l}\text { Fridman } \\
\text { et al. [16] }\end{array}$ & 1 & $\mathrm{~m}$ & 25 & RTA & MCS & $\begin{array}{l}\text { MRI: closed TBI } \\
\text { with intracranial } \\
\text { hypertension }\end{array}$ \\
\hline $\begin{array}{l}\text { Passler and } \\
\text { Riggs [15] }\end{array}$ & 5 & $\mathrm{f}: 3 ; \mathrm{m}: 2$ & $18.9(4.7)$ & 5 TBI & VS-MCS & CT: TBI \\
\hline $\begin{array}{l}\text { Krimchansky } \\
\text { et al. [14] }\end{array}$ & 8 & $\mathrm{f}: 3 ; \mathrm{m}: 5$ & 31 (108) & 8 TBI & VS & $\begin{array}{l}\text { CT: ventriculomegaly, } \\
\text { cortical atrophy }\end{array}$ \\
\hline
\end{tabular}

$n$, number; NM, not mentioned; f, female; $\mathrm{m}$, male; SD, standard deviation; NTAR, nontraumatic aneurysm rupture; HI, head injury; RTA, road traffic incident; $\mathrm{CO}$, carbon monoxide; ICH, intracranial hemorrhage; UK, unknown; SE, status epilepticus, RTA, road traffic accident; TBI, traumatic brain injury; MCS, minimally conscious state; PVS, persistent vegetative state; MRI, magnetic resonance imaging; CT, computed tomography; $\mathrm{P}$, patient; EDH, extradural hemorrhage; SDH, subdural hemorrhage.

the trauma. The authors stated that dopaminergic treatment should be considered in VS patients with extrapyramidal symptomatology and MRI evidence of dopaminergic pathway lesions. Krimchansky et al. [14] reported 8 VS patients secondary to TBI treated with dopamine (carbidopa $25 \mathrm{mg} /$ levodopa $250 \mathrm{mg}$ in a dose of $62.5 \mathrm{mg} 2$ to 3 times daily). Improvement of the state of consciousness and motor function was observed within 2 weeks. The authors argued that given the brief time-period from start of dopaminergic treatment to clinical amelioration may well reflect that the effect was primarily due to medication rather than natural recovery (Tables 1,2 ).

\section{Bromocriptine}

A gradual recovery within the first 4 weeks following bromocriptine ( $2.5 \mathrm{mg}$ twice daily) was reported by Passler and Riggs [15] in 5 VS patients (3 women and 2 men) following TBI. On the long term, 3 patients returned to school (2 graduating from high school and 1 from college), while 2 patients, although improved, still required daily support.

\section{Apomorphine}

Fridman et al. [16] reported a 25-year-old man in MCS following TBI. Neurological examination showed severe generalized spasticity without extrapyramidal signs. Initial pharmacological treatment (methylphenidate $15 \mathrm{mg}$ /day for 12 days and bromocriptine $10 \mathrm{mg} /$ day for 8 days) did not show any effect on his level of consciousness. Subsequently, apomorphine treatment was started (max. dose of $8 \mathrm{mg} \mathrm{h}^{-1}$ ). The authors reported a rapid awakening during the first hours of apomorphine administration. On day 4 of apomorphine treatment, the patient could name objects and on day 13 lift his legs. He continued to improve significantly, walking independently with a walker after 6 months of treatment and reportedly playing polo 2 years after TBI. 
Table 2. Literature review: Treatment and outcome

\begin{tabular}{|c|c|c|c|c|}
\hline First author & $\begin{array}{l}\text { Medications } \\
\text { other than main } \\
\text { dopaminergic } \\
\text { therapy }\end{array}$ & Max. dopamine-dosis & $\begin{array}{l}\text { Best clinical outcome } \\
\text { (after dopamine } \\
\text { treatment) }\end{array}$ & $\begin{array}{l}\text { Time of onset to } \\
\text { first signs of } \\
\text { improvement (from } \\
\text { timepoint of DA } \\
\text { administration) }\end{array}$ \\
\hline $\begin{array}{l}\text { Bancalari } \\
\text { et al. [11] }\end{array}$ & NM & $\begin{array}{l}\text { LD/CD } 100 / 25 \mathrm{mg} \\
\text { pos } 3 \times / d\end{array}$ & $\begin{array}{l}\text { First few words; } \\
\text { improvement of motor } \\
\text { communication skills }\end{array}$ & 4 days \\
\hline $\begin{array}{l}\text { Matsuda } \\
\text { et al. [13] }\end{array}$ & None & $\begin{array}{l}\text { P1: LD/B: } 100 / 25 \mathrm{mg} \\
\text { 2×/d. P2: LD/B } \\
\text { 100/25 mg 3×/d. } \\
\text { P3: LD/CD: } \\
100 \mathrm{mg} / 10 \mathrm{mg} 3 \times / d\end{array}$ & $\begin{array}{l}\text { P1: able to walk to high } \\
\text { school by himself. P2: } \\
\text { verbal communication. } \\
\text { P3: able to say his name } \\
\text { and address correctly }\end{array}$ & $\begin{array}{l}\text { P1: } 9 \text { days } \mathrm{P} 2: \\
8 \text { days } \mathrm{P} 3: 4 \text { days }\end{array}$ \\
\hline $\begin{array}{l}\text { Ugoya and } \\
\text { Akinyemi } \\
{[12]}\end{array}$ & None & $\begin{array}{l}\mathrm{LD} / \mathrm{CD} 375 \mathrm{mg} / \mathrm{d} \text { and } \\
250 \mathrm{mg} \text { to } 375 \mathrm{mg} / \mathrm{d}\end{array}$ & $\begin{array}{l}\text { Improvement in the } \\
\text { state of consciousness } \\
(n=9 / 11 ; 82 \%)\end{array}$ & Within 10 days \\
\hline $\begin{array}{l}\text { Fridman } \\
\text { et al. [16] }\end{array}$ & $\begin{array}{l}\text { Methylphenidate } \\
15 \mathrm{mg} / \mathrm{d} \text { for } 12 \mathrm{~d} \\
\text { (no effect); } \\
\text { bromocriptine } \\
10 \mathrm{mg} / \mathrm{d} \text { for } 8 \mathrm{~d} \\
\text { (no effect) }\end{array}$ & $\begin{array}{l}\text { Apomorphine infusion } \\
2 \mathrm{mg} \mathrm{h}^{-1} \text { to } 8 \mathrm{mg} \mathrm{h}^{-1} \\
\text { for } 12 \mathrm{~h} \text {, with } 12 \text {-h } \\
\text { rest period }\end{array}$ & Rapid awakening & $\begin{array}{l}\text { Within first few } \\
\text { hours of exposure } \\
\text { to apomorphine }\end{array}$ \\
\hline $\begin{array}{l}\text { Passler and } \\
\text { Riggs [15] }\end{array}$ & $\mathrm{NM}$ & $\begin{array}{l}\text { Bromocriptine } \\
2.5 \mathrm{mg} 2 \times / \mathrm{d}\end{array}$ & $\begin{array}{l}3 \text { patients returned to } \\
\text { school. } 2 \text { improved } \\
\text { although still requiring } \\
\text { daily support }\end{array}$ & $\begin{array}{l}\text { Improvement } \\
\text { within } 4 \text { weeks }\end{array}$ \\
\hline $\begin{array}{l}\text { Krimchansky } \\
\text { et al. [14] }\end{array}$ & $\mathrm{NM}$ & $\begin{array}{l}\text { Carbidopa } 25 \mathrm{mg} / \\
\text { levodopa } 250 \mathrm{mg} \text { : } \\
1 / 4 \text { tbl. } 3 \times / \mathrm{d}(1 \text { patient: } \\
1 / 2 \text { tbl. } 2 \times / \mathrm{d})\end{array}$ & $\begin{array}{l}\text { Improvement of state } \\
\text { of consciousness and } \\
\text { motor function }\end{array}$ & 2 weeks \\
\hline
\end{tabular}

LD/CD, levodopa/carbidopa; MCS, minimally conscious state; LD/B, levodopa/benserazide; PVS, persistent vegetative state; DA, dopamine; NM, not mentioned; VS, vegetative state; P, patient; pos, per os/oral; d, day; tbl., tablet.

\section{Discussion}

Although research in this field is still in its initial stages, dopaminergic deficit at the rely centers of consciousness, foremost the thalamo-cortico-ventral tegmental circuits, appears to represent one of the organic correlates of $\mathrm{DoC}[6,17]$. Dopamine dysfunction may well be the common denominator in DoC patients. This notion is also supported by the observation of the effectiveness of dopaminergic treatment in a variety of patients, who are heterogenous for their underlying pathophysiology causing the DoC.

The reported clinical results on Madopar in DOC are encouraging; however, they represent only class IV evidence-based furthermore on a few patients. At this stage, however, randomized double-blind placebo-controlled trials are urgently needed to arrive to definite answers regarding the effectiveness of dopaminergic medication in DoC. At current stage, only amantadine is recommended by the American practice guidelines for DoC for the treatment of post-traumatic DoC [18]. More clinical and fundamental research data are urgently needed to evaluate more exhaustively the effect of dopaminergic mono- or combination 
treatment in DOC. Additional data may also allow for stratification of DOC patients to select more accurately patients who most probably would benefit from Madopar or combination treatment.

\section{Conclusion}

Our case report of $2 \mathrm{DoC}$ patients supports the available data in the literature on the apparent beneficial dopaminergic effect in DoC. We equally observed that the level of consciousness improved within a relative short period of time of 4 weeks after treatment initiation, pointing toward a Madopar effect. Based on the literature, drug treatment was applied in most cases successfully at a later point in time ( $>28$ days) after brain damage. One of the reasons therefore is that often the focus in the early phase of treatment is on accompanying complications and vegetative dysregulation, which leave little room for additional pharmaceutical stimulation therapies. Although the mechanism of action of the various drugs needs further clarification, pharmacological treatment in DoC patients should be considered, in our opinion, at an early stage, given the otherwise poor prognosis of the disease. Confirming through class I evidence, the beneficial effects of Madopar in this pool of patients will represent a fundamental step in the treatment of DoC.

\section{Take-Home-Points}

- Persistent disorders of consciousness can in some cases recover spontaneously within 6-12 months, although longer periods of spontaneous recovery were reported.

- Data on pharmacological treatment are mainly based on class IV evidence. There are currently only a few controlled and structured therapeutic approaches available.

- It is suggested that dopaminergic treatment may contribute also to accelerated improvement within a process of natural recovery.

- Although the literature reports successful drug treatment after $>28$ days after brain damage, pharmacological treatment should be considered at an early stage given the otherwise poor prognosis of the disease.

\section{Acknowledgment}

We thank Dr. Karin Hediger for proof-reading and data preparation.

\section{Statement of Ethics}

The article is exempt from Ethical Committee approval. The article is a case report and as such does not need an Ethical Committee approval. Written informed consent was obtained from the guardianships of the patients for publication of this case report and any accompanying images.

\section{Conflict of Interest Statement}

The authors declare that there are no conflicts of interest. 
Saleh et al.: Madopar in Disorders of Consciousness

\section{Funding Sources}

None.

\section{Author Contributions}

C. Saleh wrote the first draft, analyzed the data, revised critically the final draft, and gave approval for publication. A. Andrykiewicz wrote the draft, analyzed the data, revised critically the final draft, and gave approval for publication. M. Hund-Georgiadis wrote the draft, analyzed the data, revised critically the final draft, and gave approval for publication.

\section{Data Availability Statement}

All data analyzed for this case report ( 2 case presentations) are included in this article. Further enquiries can be directed to the corresponding author.

\section{References}

1 Laureys S, Celesia GG, Cohadon F, Lavrijsen J, Leon-Carrion J, Sannita WG, et al. Unresponsive wakefulness syndrome: a new name for the vegetative state or apallic syndrome. BMC Med. 2010;8:68.

2 Jennett B, Plum F. Persistent vegetative state after brain damage. RN. 1972;35(10):ICU1-4.

3 Giacino JT, Ashwal S, Childs N, Cranford R, Jennett B, Katz DI, et al. The minimally conscious state: definition and diagnostic criteria. Neurology. 2002;58(3):349-53.

4 Nakase-Richardson R, Yablon SA, Sherer M, Nick TG, Evans CC. Emergence from minimally conscious state: insights from evaluation of posttraumatic confusion. Neurology. 2009;73(14):1120-6.

5 Ciurleo R, Bramanti P, Calabrò RS. Pharmacotherapy for disorders of consciousness: are "awakening" drugs really a possibility? Drugs. 2013 Nov;73(17):1849-62.

6 Fridman EA, Osborne JR, Mozley PD, Victor JD, Schiff ND. Presynaptic dopamine deficit in minimally conscious state patients following traumatic brain injury. Brain. 2019;142(7):1887-93.

7 Spindler LRB, Luppi AI, Adapa RM, Craig MM, Coppola P, Peattie ARD, et al. Dopaminergicbrainstem disconnection is common to pharmacological and pathological consciousness perturbation. Proc Natl Acad Sci U S A. 2021;118(30):e2026289118.

8 Wisor JP, Nishino S, Sora I, Uhl GH, Mignot E, Edgar DM. Dopaminergic role in stimulant-induced wakefulness. J Neurosci. 2001;21:1787-94.

9 Sanz LRD, Lejeune N, Blandiaux S, Bonin E, Thibaut A, Stender J, et al. Treating disorders of consciousness with apomorphine: protocol for a double-blind randomized controlled trial using multimodal assessments. Front Neurol. 2019;10:248.

10 Edlow BL, Claassen J, Schiff ND, Greer DM. Recovery from disorders of consciousness: mechanisms, prognosis and emerging therapies. Nat Rev Neurol. 2021;17(3):135-56.

11 Bancalari E, Rabinstein A, Machiavello F, Desmaison A. Accelerated emergence from a nontraumatic minimally conscious state with levodopa/carbidopa. Neurol Clin Pract. 2018;8:541-2.

12 Ugoya SO, Akinyemi RO. The place of l-dopa/carbidopa in persistent vegetative state. Clin Neuropharmacol. 2010;33:279-84.

13 Matsuda W, Matsumura A, Komatsu Y, Yanaka K, Nose T. Awakenings from persistent vegetative state: report of three cases with parkinsonism and brain stem lesions on MRI. J Neurol Neurosurg Psychiatry. 2003;74:1571-3.

14 Krimchansky BZ, Keren O, Sazbon L, Groswasser Z. Differential time and related appearance of signs, indicating improvement in the state of consciousness in vegetative state traumatic brain injury (VS-TBI) patients after initiation of dopamine treatment. Brain Inj. 2004;18:1099-105.

15 Passler MA, Riggs RV. Positive outcomes in traumatic brain injury-vegetative state: patients treated with bromocriptine. Arch Phys Med Rehabil. 2001;82:311-5.

16 Fridman EA, Krimchansky BZ, Bonetto M, Galperin T, Gamzu ER, Leiguarda RC, et al. Continuous subcutaneous apomorphine for severe disorders of consciousness after traumatic brain injury. Brain Inj. 2010;24:636-41.

17 Moustafa AA, McMullan RD, Rostron B, Hewedi DH, Haladjian HH. The thalamus as a relay station and gatekeeper: relevance to brain disorders. Rev Neurosci. 2017;28(2):203-18.

18 Giacino JT, Whyte J, Bagiella E, Kalmar K, Childs N, Khademi A, et al. Placebo-controlled trial of amantadine for severe traumatic brain injury. N Engl J Med. 2012;366(9):819-26.

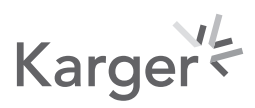

